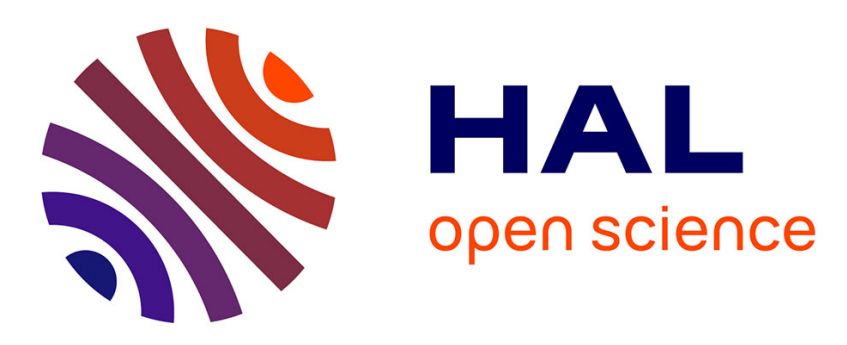

\title{
A new model of fluid flow to determine pressure balance characteristics
}

Padipat Wongthep, Thierry Rabault, Ricardo Noguera, Christophe Sarraf

\section{To cite this version:}

Padipat Wongthep, Thierry Rabault, Ricardo Noguera, Christophe Sarraf. A new model of fluid flow to determine pressure balance characteristics. Métrologia, 2013, Métrologia 50, pp.153-157. 10.1088/0026-1394/50/2/153 . hal-01082905

\section{HAL Id: hal-01082905 https://hal.science/hal-01082905}

Submitted on 14 Nov 2014

HAL is a multi-disciplinary open access archive for the deposit and dissemination of scientific research documents, whether they are published or not. The documents may come from teaching and research institutions in France or abroad, or from public or private research centers.
L'archive ouverte pluridisciplinaire HAL, est destinée au dépôt et à la diffusion de documents scientifiques de niveau recherche, publiés ou non, émanant des établissements d'enseignement et de recherche français ou étrangers, des laboratoires publics ou privés. 


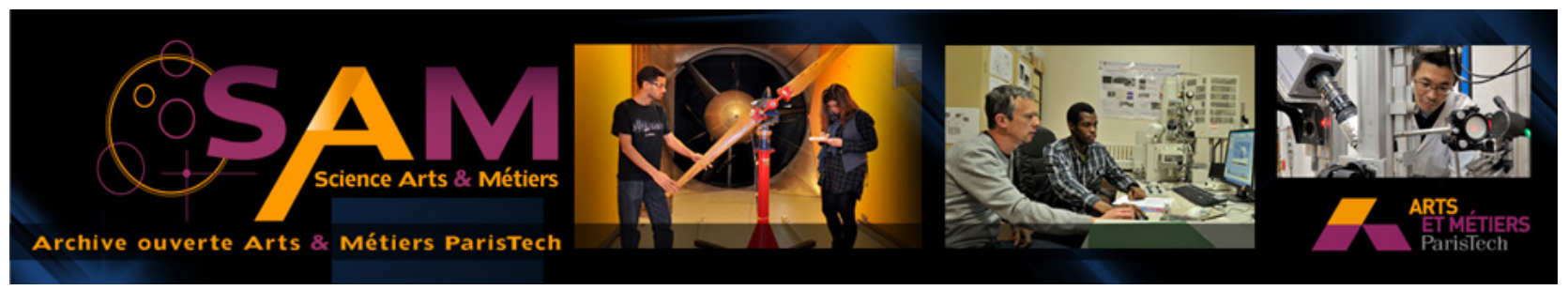

Science Arts \& Métiers (SAM)

is an open access repository that collects the work of Arts et Métiers ParisTech researchers and makes it freely available over the web where possible.

This is an author-deposited version published in: http://sam.ensam.eu

Handle ID: .http://hdl.handle.net/10985/8900

\section{To cite this version :}

Padipat WONGTHEP, Thierry RABAULT, Ricardo NOGUERA, Christophe SARRAF - A new model of fluid flow to determine pressure balance characteristics - Métrologia nMétrologia 50, p.153-157 - 2013 


\title{
A new model of fluid flow to determine pressure balance characteristics
}

\author{
P Wongthep ${ }^{1,2}$, T Rabault $^{1}$, R Noguera $^{2}$ and C Sarraf ${ }^{2}$ \\ ${ }^{1}$ LNE, 1, rue Gaston Boissier, 75724 Paris Cedex 15, France \\ ${ }^{2}$ Laboratoire de dynamique des Fluides, Ecole doctorale, Arts et Métier Paristech, 151, bd de l'Hôpital, \\ 75013 Paris, France \\ E-mail: padipat.wongthep@1ne.fr
}

\begin{abstract}
Some projects such as the EUROMET project 463 have underlined the lack of agreement between experimental measurements and calculations by the finite element method (FEM), used to determine the piston fall rate of a high-pressure balance used in primary standards. This is significant because the piston fall rate is an essential parameter to characterize experimentally the mean gap between the piston and the cylinder and to determine the effective area $\left(A_{\mathrm{p}}\right)$ at each pressure $(p)$ point. By improving the method used to estimate the piston fall rate it is possible to improve the determination of the gap, the effective area and consequently the pressure distortion coefficient. One possible cause of the lack of agreement between the calculated and measured piston fall rates could be inappropriate modelling of the fluid flow. In fact, the former quasi-1D Stokes model assimilates the gap between the piston and the cylinder as formed by two parallel walls, which is an approximation. In addition, the velocity of the piston wall was neglected. In order to evaluate the influence of this model, the equations of the fluid flow are modified and are presented in this paper. Equations that were defined in a parallel-plane model are defined in an annular gap model. In addition to this, corrections due to the velocity of the piston wall are inserted. This research work is applied on a Desgranges et Huot DH 7594 piston-cylinder unit of PTB with a pressure up to $1 \mathrm{GPa}$, in the continuity of the EUROMET project 463 in order to quantify the influence of each correction that has been inserted in the new equations. This is carried out using the FEM. This analysis will allow us to evaluate the improvement of our knowledge of the behaviour of piston gauges and consequently to better evaluate the uncertainties due to the models.
\end{abstract}

\section{Introduction}

Pressure balances are used in many national metrology institutes (NMIs) as a primary pressure standard from a few kilopascals up to approximately $1 \mathrm{GPa}$. The pressure balance consists of a loaded piston inserted into a closely fitted cylinder. The effective area $\left(A_{\mathrm{p}}\right)$ of the piston-cylinder unit (PCU) is commonly defined as a function of the effective area at zero pressure $\left(A_{0}\right)$, the pressure applied $(p)$ and the pressure distortion coefficient $(\lambda)$ :

$$
A_{\mathrm{p}}=A_{0}(1+\lambda p)
$$

For pressures above $10 \mathrm{MPa}, \lambda$ contributes significantly to the final uncertainty. That is why its evaluation is so critical and why many studies have been carried out on this subject. The EUROMET project 463 [1] was organized in 1998 to compare the agreement between laboratory calculations of $\lambda$ and also the piston fall rate $\left(v_{\mathrm{f}}\right)$ using the finite element method (FEM). The PCU of PTB (No DH 7594) for a pressure balance, which operates at pressure up to $1 \mathrm{GPa}$, was selected to compare the calculations. Large differences in the pressure distributions, gap profiles and particularly $v_{\mathrm{f}}$ at the maximum pressure were found [1]. The measurement of $v_{\mathrm{f}}$ is an important point to check the equilibrium condition for the comparison (the crossfloating method) of two pressure balances and the quality of the pressure balance and PCU. Moreover, it has to be remembered that $v_{\mathrm{f}}$ can be used to visualize the effect of the piston and cylinder distortions on the pressure balances. 


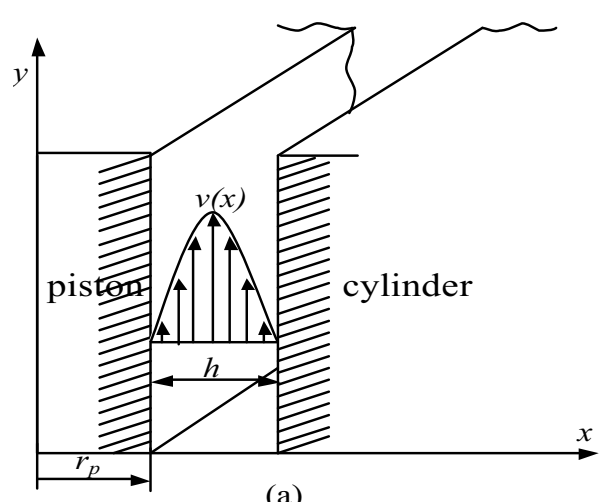

(a)

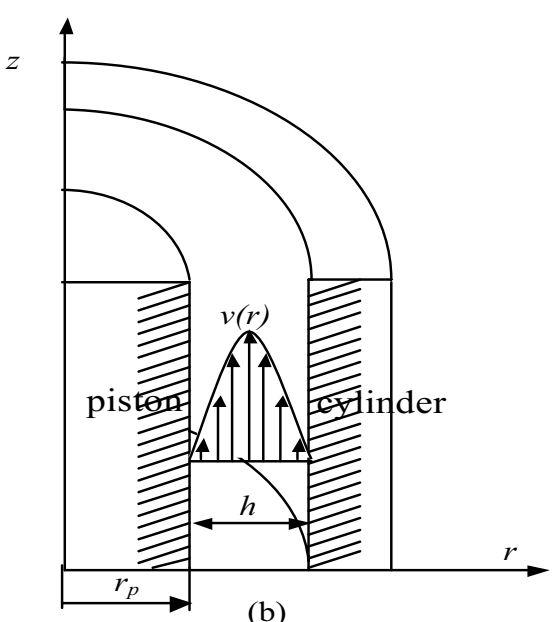

(b)

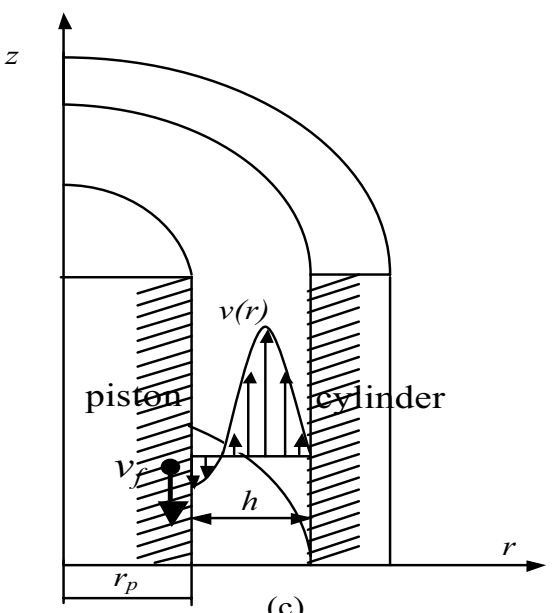

(c)

Figure 1. Calculation models: $(a)$ parallel-plane model, $(b)$ annular gap model with zero velocity imposed as the boundary condition on the piston side, $(c)$ annular gap model with fall velocity imposed as the boundary condition on the piston side.

\section{Theory}

The equilibrium of the PCU is a condition where fluid dynamics laws apply. Therefore, the velocity profile of the fluid moving through a gap between the piston and the cylinder as a function of variation in pressure at both ends of the pistoncylinder engagement length of the PCU can be determined by applying the Navier-Stokes equation [2]:

$$
\frac{\mathrm{d} v}{\mathrm{~d} t}=-\frac{1}{\rho} \operatorname{grad} p+v \Delta v+\left(\frac{\xi}{\rho}+\frac{v}{3}\right) \operatorname{grad} \operatorname{div} v+F,
$$

where $v$ is the fluid velocity, $\rho$ is the fluid density, $p$ is the applied pressure, $v$ is the kinematic viscosity, $\xi$ is the second viscosity and $F$ is the mass force of the fluid. The following realistic assumptions are made:

- fluid is incompressible ( $\operatorname{div} v=0$ ),

- fluid flows are stationary, isothermal and laminar $(\mathrm{d} v / \mathrm{d} t=0)$

- mass force is negligible $(F=0)$,

- one-dimensional flow in the $y$ direction for the parallelplane model and in the $z$ direction for the annular gap model.

Then the equation can be modified as

$$
\eta \Delta v=\operatorname{grad} p .
$$

The Laplace operator $\Delta v$ depends on the coordinate systems. In the models used until now, the gap between the piston and the cylinder was assumed to be based on parallel surfaces and the fluid velocity at each surface to be equal to zero. The calculations were performed with a parallel-plane model similar to the model used by Dadson et al [3]. In this work, a cylindrical model, more consistent with the geometry of the PCU, is applied and the piston velocity is taken into account. For this paper, the following flow models are used (figure 1):

- model 1 is the parallel-plane model in (4),

- model 2 is the annular gap model with zero velocity imposed as the boundary condition on the piston side in (5),

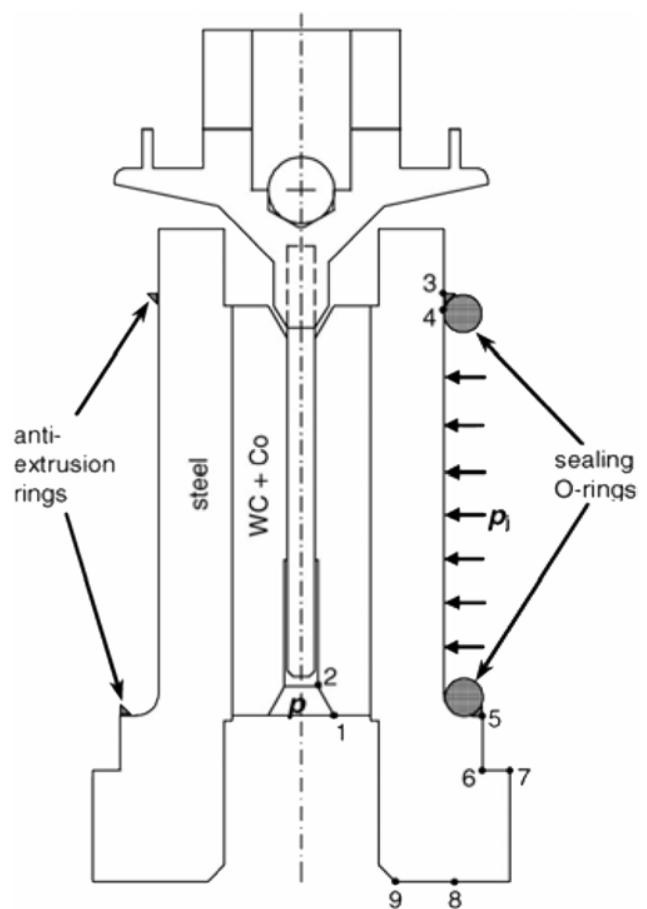

Figure 2. Piston-cylinder assembly DH 7594.

- model 3 is the annular gap model with fall velocity imposed as the boundary condition on the piston side in (6).

The equations of the three models are

$$
\begin{aligned}
v(x)= & \frac{1}{2 \eta} \frac{\mathrm{d} p}{\mathrm{~d} y}\left(x^{2}-r_{\mathrm{p}}+\frac{\left(r_{\mathrm{p}}+h\right)^{2}-r_{\mathrm{p}}^{2}}{h}\left(r_{\mathrm{p}}-x\right)\right) \\
v(r)= & \frac{1}{4 \eta} \frac{\mathrm{d} p}{\mathrm{~d} z}\left(r^{2}-\left(r_{\mathrm{p}}+h\right)^{2}+\left(\left(r_{\mathrm{p}}+h\right)^{2}-r_{\mathrm{p}}^{2}\right)\right. \\
& \left.\times \ln \left(\frac{r_{\mathrm{p}}+h}{r}\right) / \ln \left(\frac{r_{\mathrm{p}}+h}{r_{\mathrm{p}}}\right)\right) \\
v(r)^{*}= & v(r)+v_{\mathrm{f}} \ln \left(\frac{r_{\mathrm{p}}+h}{r}\right) / \ln \left(\frac{r_{\mathrm{p}}+h}{r_{\mathrm{p}}}\right)
\end{aligned}
$$




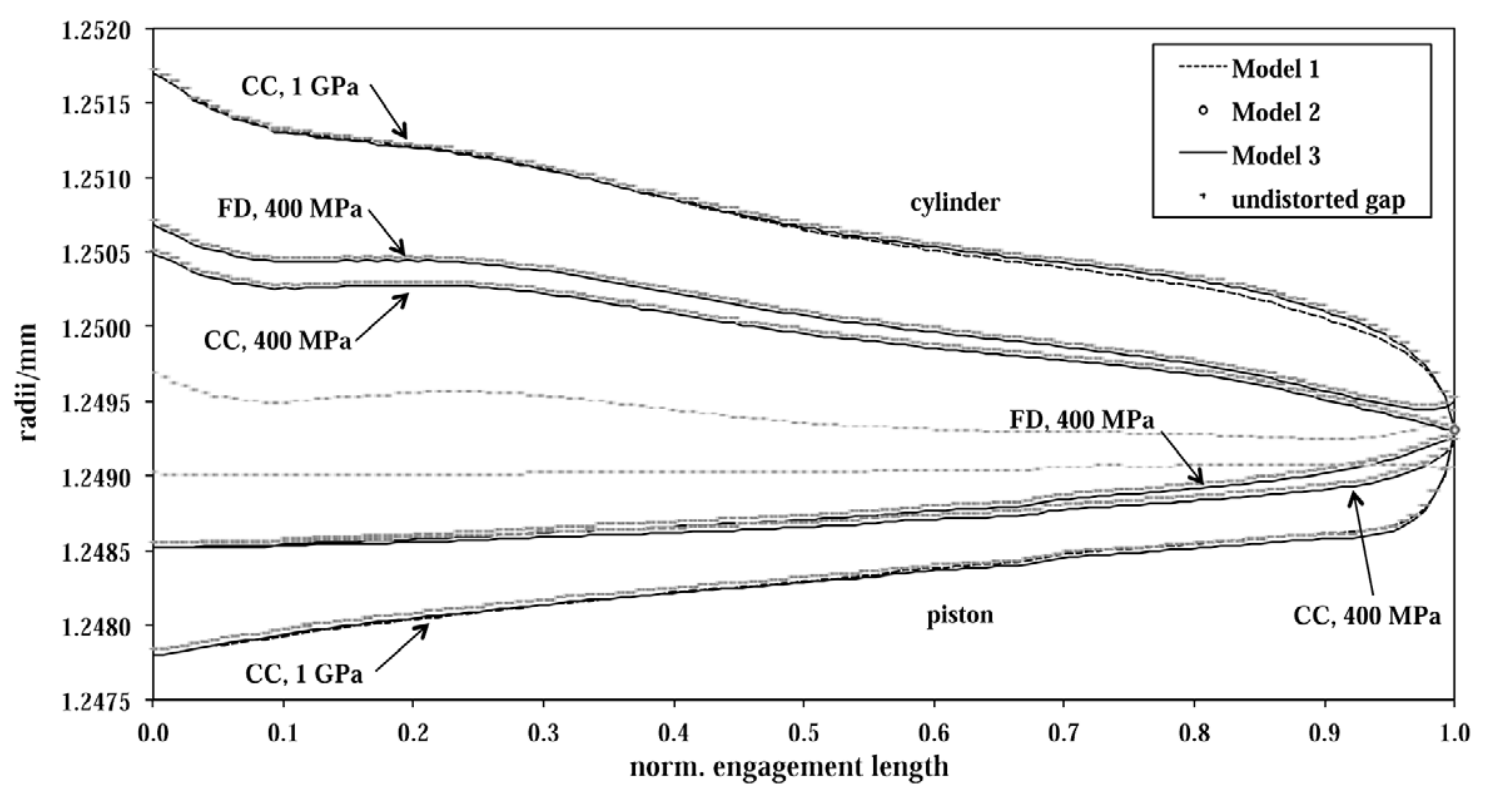

Figure 3. Gap between distorted piston and cylinder calculated by the difference models for the FD mode at $400 \mathrm{MPa}$ and for the CC mode at $400 \mathrm{MPa}$ and $1 \mathrm{GPa}$.

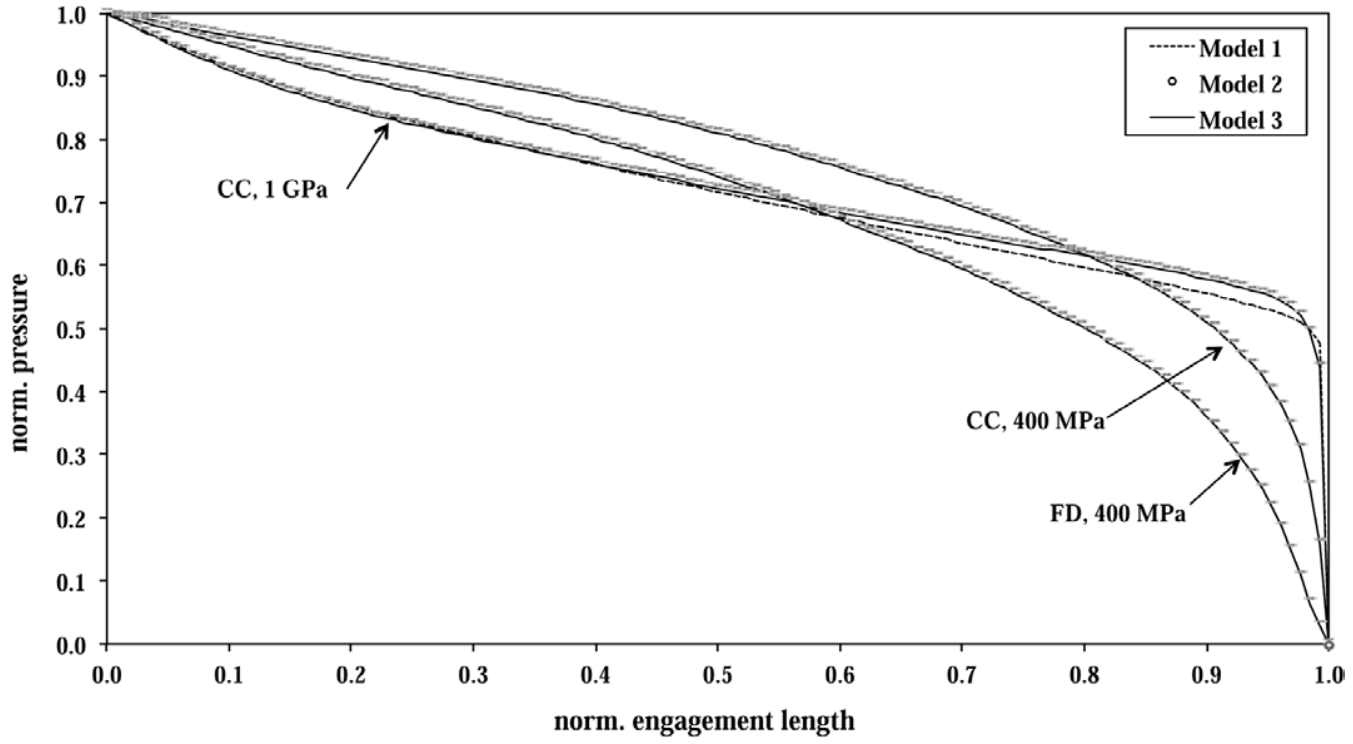

Figure 4. Normalized pressure distribution along the gap calculated by the difference models for the FD mode at $400 \mathrm{MPa}$ and for the CC mode at $400 \mathrm{MPa}$ and $1 \mathrm{GPa}$.

where $\eta$ is the dynamic viscosity, $\mathrm{d} p / \mathrm{d} y$ and $\mathrm{d} p / \mathrm{d} z$ are the variation of the pressure along the $y$ direction and $z$ direction, $r_{\mathrm{p}}$ is the piston radius and $h$ is the gap width.

\section{Numerical application}

The numerical calculations are performed with the Structural Dynamics toolbox (SDTools) in MatLab, which allows the application of the FEM. A common method is the separated solution of the fluid flow and structural problem. The fluid flow was analysed in the piston-cylinder clearance, which is affected by structural distortions. Piston/cylinder distortions are determined iteratively by the FEM structural analysis. The pressure distribution obtained by flow analysis is at the same time used as the load condition in the structure problem.
The solution of the two-coupled problems is determined by structural and fluid flow analysis performed iteratively until a convergence of the output parameters of interest is obtained. The mesh is obtained by using the Gmsh software [4] to define the contour of structure of the PCU. A module is created in order to integrate the mesh within the Matlab software. The calculation performed for the real profile of the undistorted gap between the piston and the cylinder obtained by dimensional measurements, and the elastic constants of materials are taken as initial parameters as specified in section 2 of the EUROMET project 463 [1]. A sketch of the piston-cylinder assembly is shown in figure 2 [1].

The pressure distribution in the gap was calculated by applying equations (4), (5) and (6) and by taking into account the variable fluid characteristics (density and viscosity) in 
the gap between the piston and the cylinder. Therefore, to calculate the pressure distribution, the fluid density $(\rho)$ and dynamic viscosity $(\eta)$ need to be known. Di(2)-ethyl-hexylsebacate (DHS) is the fluid most commonly used in a pressure balance. The experimental data on DHS density and viscosity are available in [5,6] and were evaluated in [7]. For our calculation, the dynamic viscosity based on data from [5, 6] was described for a temperature of $20^{\circ} \mathrm{C}$ by the model equation

$$
\eta(p, t)=\eta(t) \times 10^{\alpha(t) \times p^{q}},
$$

where $\eta(t)$ is the dynamic viscosity, which at $t=20^{\circ} \mathrm{C}$ is equal to $0.02868 \mathrm{~Pa} \mathrm{~s}, \alpha(t)$ is the coefficient, which at $t=20^{\circ} \mathrm{C}$ is equal to $0.01729, p$ is the applied pressure in megapascals and $q$ is a coefficient equal to 0.8 .

\section{Results}

The calculations of pressure distortion coefficients and piston fall rate for the piston-cylinder unit DH 7594 were performed by the FEM at pressure $p$ in the range $50 \mathrm{MPa}$ to $1 \mathrm{GPa}$ in the free deformation (FD) and controlled-clearance (CC) modes. For the CC mode, the jacket pressure $\left(p_{\mathrm{j}}\right)$ applied is equal to $0.1 p$. The gap profiles and the pressure distributions are shown in figures 3 and 4 , respectively.

The gap profiles between the three calculation models at $400 \mathrm{MPa}$ for the FD and CC modes are very similar to each other. And the pressure distributions along the gap are also very similar. At $1 \mathrm{GPa}$ for the $\mathrm{CC}$ mode, the differences in the gap profiles between the three calculation models occurred near the gap outlet. The gap profiles between models 2 and 3 are the same. The maximum differences in the piston and cylinder radii between model 1 and model 2 (or model 3) are $42 \mathrm{~nm}$ and $50 \mathrm{~nm}$, respectively, near the gap outlet.

At $1 \mathrm{GPa}$ for the $\mathrm{CC}$ mode, the pressure distributions along the gap between models 2 and 3 are very similar to each other but they are higher than model 1 near the gap outlet. The maximum difference in pressure in the gap between model 2 (or model 3) and model 1 is $38 \mathrm{MPa}$ near the gap outlet.

The maximum difference in $A_{\mathrm{p}}$ between the parallel-plane and annular gap models is equal to $6 \times 10^{-6} \mathrm{~mm}^{2}$ or equivalent to $1.22 \times 10^{-6}$ and the maximum difference in $\lambda$ is equal to $0.001 \times 10^{-6} \mathrm{MPa}^{-1}$ with $p$ equal to $1 \mathrm{GPa}$ for the $\mathrm{CC}$ mode (table 1).

The maximum differences in $v_{\mathrm{f}}$ between model 1 and model 2 (or model 3) are $0.0143 \mathrm{~mm} \mathrm{~min}^{-1}$ and $0.00078 \mathrm{~mm} \mathrm{~min}^{-1}$ with $p$ equal to $1 \mathrm{GPa}$ for the FD mode and CC mode, respectively. The maximum differences in $\lambda$ and $v_{\mathrm{f}}$ between calculation and experimental methods for the FD mode are $0.012 \times 10^{-6} \mathrm{MPa}^{-1}$ and $-0.118 \mathrm{~mm} \mathrm{~min}^{-1}$, respectively, at pressure $400 \mathrm{MPa}$. For the $\mathrm{CC}$ mode, they are $-0.053 \times 10^{-6} \mathrm{MPa}^{-1}$ and $-0.052 \mathrm{~mm} \mathrm{~min}^{-1}$ at pressure $1 \mathrm{GPa}$ (table 2).

The uncertainties of the pressure distortion coefficient are summarized in table 3. These uncertainties are calculated by simulating variations of each influence parameter in their estimated range of variations [1].
Table 1. Comparisons of the FEM results for the CC mode obtained with the three different fluid models: model 1 (parallel plane), model 2 (annular gap with zero velocity at the piston side) and model 3 (annular gap with piston fall velocity at the piston side), at pressure $1 \mathrm{GPa}$ and a jacket pressure equal to $0.1 p$.

\begin{tabular}{|c|c|c|c|}
\hline Model & Model 1 & Model 2 & Model 3 \\
\hline \multicolumn{4}{|c|}{ Displacement at the gap entrance $\mu \mathrm{m}$} \\
\hline Piston & -1.199 & -1.199 & -1.199 \\
\hline Cylinder & 2.031 & 2.029 & 2.029 \\
\hline Gap width & 3.902 & 3.900 & 3.900 \\
\hline \multicolumn{4}{|c|}{ Displacement at the gap exit/ $\mu \mathrm{m}$} \\
\hline Piston & 0.250 & 0.258 & 0.258 \\
\hline Cylinder & -0.116 & -0.113 & -0.113 \\
\hline Gap width & 0.019 & 0.014 & 0.014 \\
\hline Zero effective area $/ \mathrm{mm}^{2}$ & 4.902139 & 4.902139 & 4.902139 \\
\hline $\begin{array}{l}\text { Distortion effective } \\
\text { area/mm } / \mathrm{mm}^{2}\end{array}$ & 4.904013 & 4.904007 & 4.904007 \\
\hline Piston fall rate/mm $\min ^{-1}$ & 0.05280 & 0.05202 & 0.05202 \\
\hline $\begin{array}{l}\text { Pressure distortion } \\
\text { coefficient } / 10^{-6} \mathrm{MPa}^{-1}\end{array}$ & 0.382 & 0.381 & 0.381 \\
\hline
\end{tabular}

Table 2. Pressure distortion coefficients $(\lambda)$ and piston fall rates $\left(v_{\mathrm{f}}\right)$ calculated with model 1 (parallel plane) and their deviations from the experimental data obtained by PTB $\left(\lambda=0.816 \times 10^{-6} \mathrm{MPa}^{-1}\right.$ and $v_{\mathrm{f}}=0.412 \mathrm{~mm} \mathrm{~min}^{-1}$ for applied pressure $400 \mathrm{MPa}$ in the FD mode; $\lambda=0.435 \times 10^{-6} \mathrm{MPa}^{-1}, v_{\mathrm{f}}=0.190 \mathrm{~mm} \mathrm{~min}^{-1}$ for applied pressure $400 \mathrm{MPa}$ and $v_{\mathrm{f}}=0.105 \mathrm{~mm} \mathrm{~min}^{-1}$ for applied pressure $1 \mathrm{GPa}$ in the $\mathrm{CC}$ mode).

\begin{tabular}{|c|c|c|c|c|}
\hline $\begin{array}{l}p / \\
\text { MPa }\end{array}$ & $\begin{array}{l}\lambda / \\
10^{-6} \mathrm{MPa}^{-1}\end{array}$ & $\begin{array}{l}\left(\lambda-\lambda_{\text {exp. } .}\right) / \\
10^{-6} \mathrm{MPa}^{-1}\end{array}$ & $\begin{array}{l}v_{\mathrm{f}} / \\
\mathrm{mm} \min ^{-1}\end{array}$ & $\begin{array}{l}\left(v_{\mathrm{f}}-v_{\mathrm{f}, \exp } .\right) / \\
\mathrm{mm} \min ^{-1}\end{array}$ \\
\hline \multicolumn{5}{|c|}{ Free deformation $(F D)$ mode } \\
\hline 400 & 0.828 & 0.012 & 0.294 & -0.118 \\
\hline \multicolumn{5}{|c|}{ Controlled clearance $(C C)$ mode } \\
\hline 400 & 0.425 & -0.010 & 0.149 & -0.041 \\
\hline 1000 & 0.382 & -0.053 & 0.053 & -0.052 \\
\hline
\end{tabular}

\section{Conclusion}

The pressure distortion coefficient and particularly the piston fall rate of PCU DH 7594 used for the pressure balance up to $1 \mathrm{GPa}$ were determined by applying new models of fluid flow. The experimental values given by PTB were compared with those calculated by the finite element methods. The two calculations of the pressure distortion coefficient in the Cartesian and cylindrical geometry models, performed with and without taking into account the fluid velocity at the falling piston surface, are in good agreement. They are also in good agreement with the experimental data under the uncertainty claimed for the PTB experimentation. The piston fall rates calculated for the parallel-plane and annular gap models are also in good agreement, but there is still a large difference from the experimental data (figure 5). It was shown that the fluid flow in the annular gap model and the boundary condition of the fluid velocity at the piston surface have no significant effect on the pressure distortion coefficient, and the piston fall rate provided by calculation. Therefore, these results cannot show that the uncertainty calculation is better than model 1 (table 3). As for the axial symmetry of the problem, one of 
A new model of fluid flow to determine pressure balance characteristics

Table 3. Main sources of uncertainty and overall standard uncertainty of the pressure distortion coefficient in the FD and CC modes at $400 \mathrm{MPa}$ and $1 \mathrm{GPa}$ with different models (all values in units of $10^{-6} \mathrm{MPa}^{-1}$ ).

\begin{tabular}{|c|c|c|c|c|c|c|c|c|c|}
\hline \multirow[b]{2}{*}{ Uncertainty source } & \multicolumn{3}{|c|}{ FD mode, $400 \mathrm{MPa}$} & \multicolumn{3}{|c|}{$\mathrm{CC}$ mode, $400 \mathrm{MPa}$} & \multicolumn{3}{|c|}{$\mathrm{CC}$ mode, $1 \mathrm{GPa}$} \\
\hline & Model 1 & Model 2 & Model 3 & Model 1 & Model 2 & Model 3 & Model 1 & Model 2 & Model 3 \\
\hline$E_{\text {cyl }}$ & 0.0240 & 0.0241 & 0.0241 & 0.0155 & 0.0156 & 0.0156 & 0.0150 & 0.0150 & 0.0150 \\
\hline$\mu_{\mathrm{cyl}}$ & 0.0048 & 0.0048 & 0.0048 & 0.0038 & 0.0038 & 0.0038 & 0.0038 & 0.0038 & 0.0038 \\
\hline$E_{\mathrm{pst}}$ & 0.0032 & 0.0032 & 0.0032 & 0.0030 & 0.0030 & 0.0030 & 0.0038 & 0.0038 & 0.0038 \\
\hline$\mu_{\mathrm{pst}}$ & 0.0054 & 0.0054 & 0.0054 & 0.0056 & 0.0056 & 0.0056 & 0.0052 & 0.0052 & 0.0052 \\
\hline$E_{\text {slv }}$ & 0.0007 & 0.0007 & 0.0007 & 0.0013 & 0.0013 & 0.0013 & 0.0023 & 0.0023 & 0.0023 \\
\hline$\mu_{\mathrm{slv}}$ & 0.0002 & 0.0002 & 0.0002 & 0.0050 & 0.0050 & 0.0050 & 0.0048 & 0.0048 & 0.0048 \\
\hline Piston radius & 0.0104 & 0.0104 & 0.0104 & 0.0134 & 0.0134 & 0.0134 & 0.0017 & 0.0017 & 0.0017 \\
\hline Cylinder radius & 0.0157 & 0.0157 & 0.0157 & 0.0202 & 0.0202 & 0.0202 & 0.0026 & 0.0026 & 0.0026 \\
\hline Piston conicity & 0.0050 & 0.0050 & 0.0050 & 0.0227 & 0.0227 & 0.0227 & 0.0015 & 0.0015 & 0.0015 \\
\hline Cylinder conicity & 0.0565 & 0.0565 & 0.0565 & 0.0338 & 0.0338 & 0.0338 & 0.0115 & 0.0115 & 0.0115 \\
\hline Overall standard uncertainty & 0.065 & 0.065 & 0.065 & 0.051 & 0.051 & 0.051 & 0.021 & 0.021 & 0.021 \\
\hline
\end{tabular}

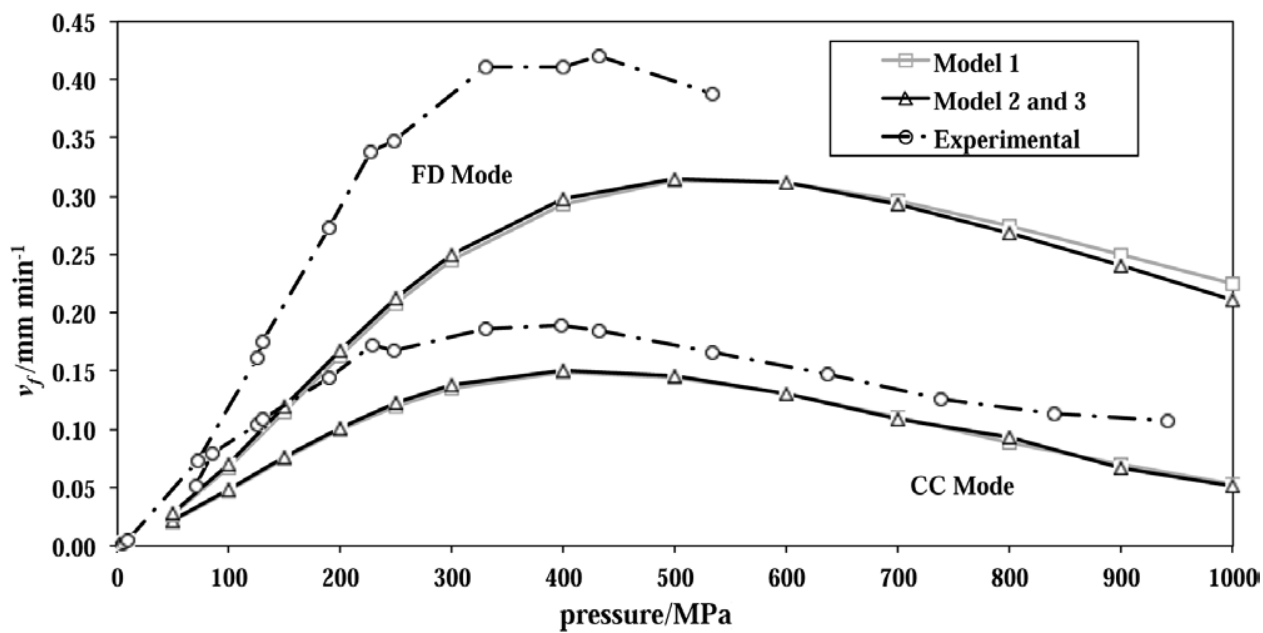

Figure 5. Piston fall rate $\left(v_{\mathrm{f}}\right)$ in the FD and CC modes measured experimentally and calculated in different models: model 1 (parallel plane), model 2 (annular gap with zero velocity at the piston side) and model 3 (annular gap with piston fall velocity at the piston side).

the possible deviations of PCUs is non-coaxiality of the piston and cylinder bore manifested by a displacement or a tilt of the piston with respect to the cylinder bore axis. On the other hand, this difference can be explained by the dimensional properties of the cylinder at the gap inlet and outlet. To understand this difference, the authors will focus on the geometry of the piston and cylinder bore. This new method will be applied to LNE's PCU for the pressure balance up to $1 \mathrm{GPa}$.

\section{References}

[1] Sabuga W, Molinar G, Buonanno G, Esward T, Legras J C and Yagmur L 2006 Finite element method used for calculation of the distortion coefficient and associated uncertainty of a PTB $1 \mathrm{GPa}$ pressure balance-EUROMET project 463 Metrologia 43 311-25
[2] Yavorski B and Detlaf A 1975 Aide-mémoire de physique (Moscow: Mir) pp 334-5

[3] Dadson R S, Lewis S L and Peggs G N 1982 The Pressure Balance: Theory and Practice (London: HMSO)

[4] Geuzaine C and Remacle J F 2009 Gmsh: a three-dimensional finite element mesh generator with built-in pre- and post-processing facilities Int. J. Numer. Methods Eng. 79 1309-31

[5] ASME 1953 Viscosity and density of over 40 lubricating fluids of known composition at pressures to 150,000 psi and temperatures to $425^{\circ} \mathrm{F}$ ASME Report (New York: American Society of Mechanical Engineers)

[6] Vergne P 1990 New high pressure viscosity measurements on di(2-ethylhexyl) sebacate and comparison with previous data High Temp.-High Press. 22 613-21

[7] Molinar G F 1998 EUROMET project Number 463, Density and dynamic viscosity versus pressure, up to $1 \mathrm{GPa}$, for the di(2) ethyl-hexyl-sebacate fluid at $20^{\circ} \mathrm{C}$ Rapporto Interno $R$ 486 CNR-IMGC (Torino, December 1998) 